\title{
The Portuguese Contribution for lab2go - pt.lab2go
}

\author{
http://dx.doi.org/10.3991/ijoe.v9iS1.2349 \\ M.T. Restivo ${ }^{1}$ and A. Cardoso ${ }^{2}$ \\ ${ }^{1}$ UISPA, IDMEC-Pólo FEUP, Faculty of Engineering, University of Porto, Porto, Portugal \\ ${ }^{2}$ CISUC - University of Coimbra, Coimbra, Portugal
}

\begin{abstract}
Online experimentation provides innovative and valuable tools for use in academy, in high schools, in industry and in medical areas. It has also become a precious tool for educational and training purposes in any of those areas. Looking at online experimentation as a pure distance learning tool it represents a very efficient way of sharing hands-on capabilities, for example with developing countries. In Portugal a new consortium of online experimentation was created for fostering the national potential, using the Portuguese version of lab2go web platform, pt.lab2go. The authors pretend to demonstrate some of capabilities of the consortium in sharing online labs.
\end{abstract}

Index Terms - online labs, virtual reality, computer experiments, lab2go.

\section{INTRODUCTION}

Online experimentation, using emerging technology, relies on the access to online labs for educational, industrial, medical or research uses. Those resources can be experiments of remote, virtual or hybrid type. An online lab is a set of experiments offering physical set-ups available for online accessing or simulations of online experimental procedures and/or virtual "devices/systems" or even mixing both in the same user friendly interface environment. So, they can be remotely accessed or, if they are purely of virtual type, they can even be downloadable to the user computer. A hybrid laboratory is a set of experiments using remote equipment and virtual simulations, providing both remote and virtual experiments in the same effective interaction mode.

\section{The Portuguese CONTRIBUtion}

Experiment@Portugal [1] was a one year project, funded by the Calouste Gulbenkian Foundation. It ended in 2011 and its main goal has been the creation of the Portuguese Consortium of Online Labs, including all groups working in remote, virtual and hybrid experiments in the country, interested in integrating this initiative. The Faculty of Engineering of University of Porto (FEUP) and the Faculty of Sciences and Technology of the University of Coimbra (FCTUC) were the host institutions of this project. At the present the authors created the experiment@portugal, a Web page for disseminating the Portuguese Consortium of Online Labs http://www.fe.up.pt/experimentaportugal/. This web page, at the level named Ontology, also provides a synthesis of the international ontology proposed by GOLC [2], where animations exemplify different types of labs: remote, virtual and hybrids.
At "Laboratories" level, the web page offers video clips from different types of experiments and its main goal is, in the future, to provide a first contact and a persuasive way based in multimedia contents of many of the available resources, inviting visitors to explore pt.lab2go resources.

The authors consider this consortium as fundamental for linking all the initiatives and making them together as a set of different tools for education, lifelong training at industrial level and also for K-12 use. All the resources are organized in Portuguese in order to make them available for the Portuguese speaking community mainly in the country, in Brazil and in Africa or in any other place (the Portuguese language is the $5^{\text {th }}$ most spoken language, with around 236 million native speakers and is the second language for around 36.8 million people, which leads to a total of around 273 million Portuguese speakers in the world).

The project has also been concerned with the dissemination of the consortium. This started with the $1^{\text {st }}$ Experiment@International Conference, exp.at'11, hosted by the Calouste Gulbenkian Foundation in November 2011 (now located at http://www.fe.up.pt/exp.at2011/).

The project's main result is now broadcasted in many different Portuguese and Brazilian web pages, and partners intend to offer the English version in the future.

\section{The Portuguese Version (PT.)LAB2GO}

The central objective of the project was to create a platform for providing materials and access to remote, virtual and hybrid experiments in different areas, based on an implemented survey of all RVLs available in Portugal. The International Association for Online Engineering (IAOE) and the GOLC Consortium (The Global Online Laboratory Consortium) offered to the project the possibility of using the lab2go platform created in the Carinthia University of Applied Sciences, Austria, in order to be built its Portuguese version pt.lab2go, which can be found and explored in (http://pt.lab2go.net/).

The platform integrates, using a uniform description and presentation, a database with the characterization of RVLs according to proposed ontology of lab2go [2], and supported by a search engine of information associated to each RVL resource. A screenshot of the main web page of pt.lab2go is shown in (Fig. 1).

\section{EXPERIMENTS@(PT.)LAB2GO}

Presently, the pt.lab2go web platform includes 49 different categories of online experiments, included in 13 laboratories from 7 Portuguese high education institutions. 


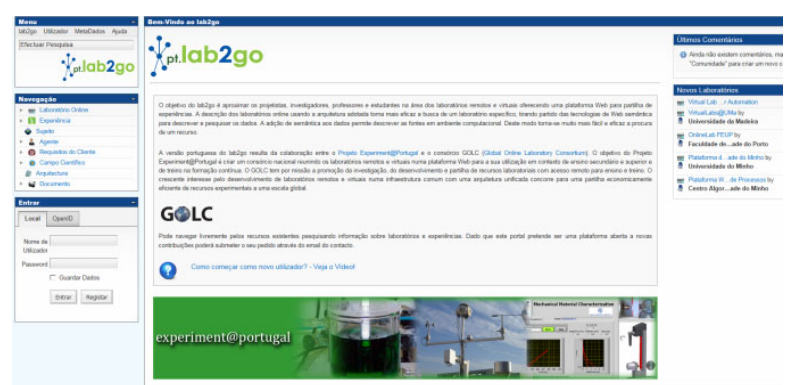

Figure 1. Main page of the pt.lab2go platform.

Some examples of different types of online experiments are presented in the following sections.

\section{A. Straightness Evaluation}

This adaptable experiment is used for the straightness evaluation of a line in a given direction on a surface. This property is important in the engineering estimation of geometric errors and for guaranteeing accuracy in manufacturing and assembling processes. The set-up interface allows the user to start the process. When this starts, the light is switched on, the on-off switch of the digital dial is pressed by an electric solenoid and this starts to move along a direction, after user definitions. The email address must be introduced for getting the test data for later straightness determination. An IP camera feeds the interface with live video, (Fig. 2).

\section{B. The RVL@DEI-FCTUC}

The Remote and Virtual Lab (RVL@DEI-FCTUC) is a hybrid web based platform with interactive computer applications that allows users to carry out virtual and remote experiments using real systems that can be remotely or locally accessed and controlled through a web browser. The platform is under development to provide online experiments (Fig. 3) integrated in an intelligent tutoring system with mechanisms to identify, monitor and supervise the users' behavior and evolution that could improve the users' performance and the achievement of the tasks proposed in different courses.

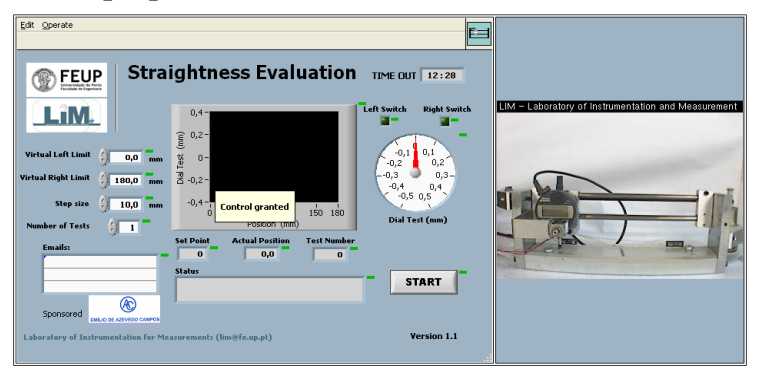

Figure 2. The Meteorological Station @ FEUP.

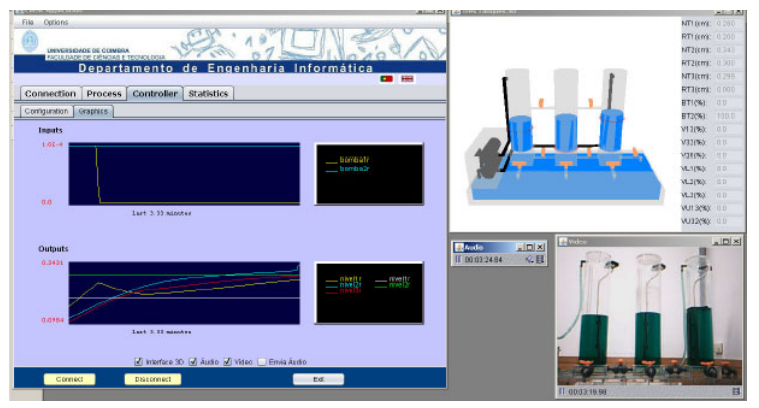

Figure 3. An experiment of the RVL@DEI-FCTUC.

\section{The LABVIRTUAL @DEQ-FCTUC}

The LABVIRTUAL (http://labvirtual.eq.uc.pt) is a virtual lab developed by the Chemical Engineering Departments of FCTUC and FEUP, in Portugal. It is an integrated platform to teach Chemical Processes, which addresses the main areas of Chemical Engineering: the portal is organized in three sections: fundaments, simulation modules and case studies. The portal (Fig. 4) includes multimedia libraries, simulators and online experiments, enabling the users to visualize some basic phenomena and mechanisms on which the design of chemical processes is based.

\section{Small Scale Model for Seepage Studies}

Groundwater flow (seepage) is an important physical phenomenon in civil engineering. Equipment for small scale experimental studies of groundwater flow is available under scheduling demonstrations. A good match is typically achieved between experimental results and numerical simulations using current commercial software packages. The equipment is a versatile teaching tool for soil mechanics and geotechnical students. The equipment allows creating different configurations such as the flow into a cofferdam, under a curtain, or through an earth dam (Fig. 5) [3].

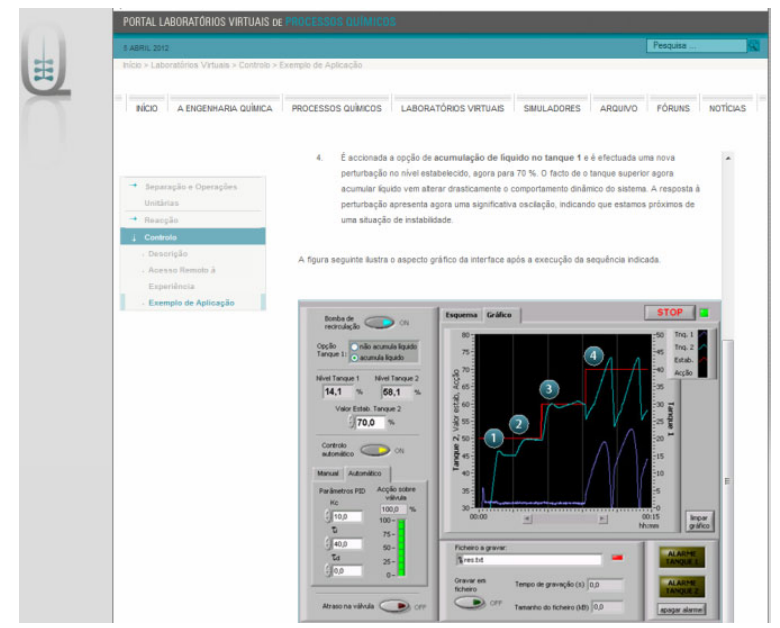

Figure 4. The LABVIRTUAL Portal @ DEQ-FCTUC.

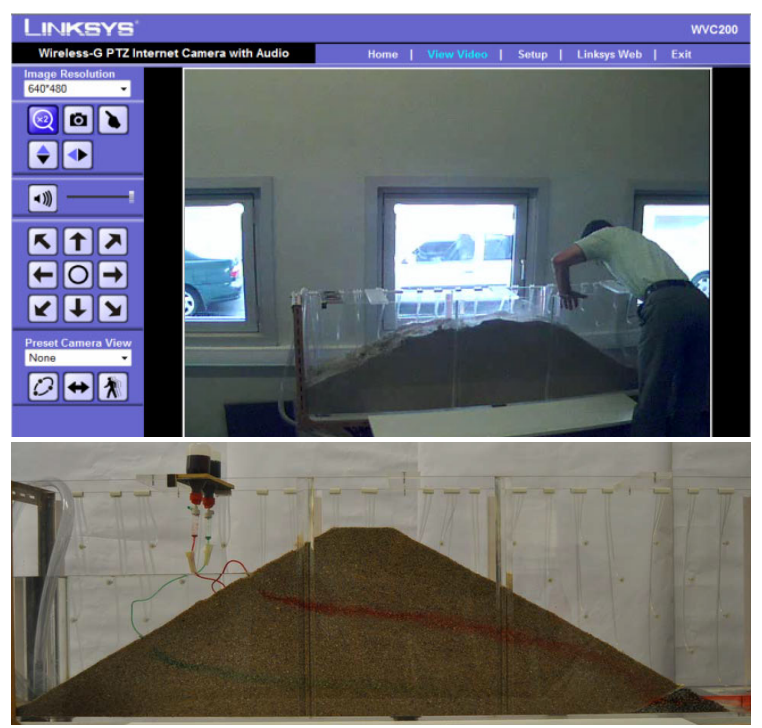

Figure 5. Experiment preparation (top) transmitted by IP camera and the test result (down). 


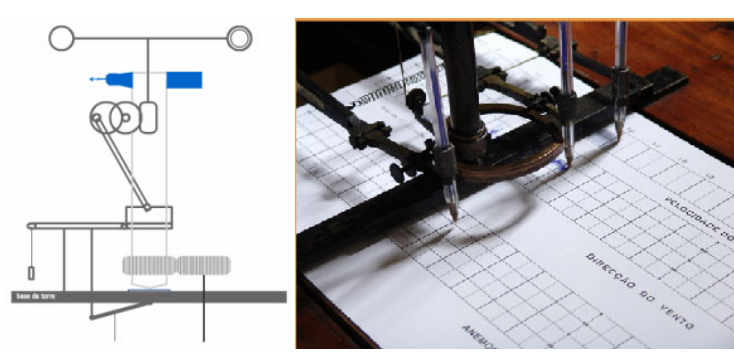

Figure 6. One level of the system infography (left) and the real recording system (right).

\section{E. The Herman Anemograph}

An anemometer is any instrument that measures the wind speed. If the anemometer also records the wind speed then it is named an anemograph. An infography of an old mechanical device is available, trying to explain, step by step, the old system and also it includes different pictures from the real mechanical system (Fig. 6), still working at the present at Observatório da Serra do Pilar da Universidade do Porto, were was mounted in 1887.

\section{FINAL DISCUSSION}

The pt.lab2go Web platform was established with 7 academic partners, offering 13 labs and 49 online experiments from very distinct areas, covering physics, mechatronics, electronics, chemistry, automation, industrial automation, elementary math, civil engineering, etc. It is open to any newcomer and the authors look to increase it, hoping to reach such a huge community of the Portuguese speaking countries. During the Exhibition Session @ REV2012 different resources were demonstrated.

Besides, the experiment@portugal Web page (http://www.fe.up.pt/experimentaportugal) received an Honorable Mention on Blended Learning from the 2012 International E-Learning Awards, Academic Division of the International E-Learning Association (IELA).

\section{ACKNOWLEDGMENT}

The authors wish to thank the Calouste Gulbenkian Foundation for funding this project and acknowledge the support of FEUP and FCTUC. It is also important to thank all the colleagues collaborating with the project and all who have been working in all different labs along their existence, creating them and, not less important, to those who still help to keep the experiments running. Many other institutions have been also funding all these resources and all of them deserve special recognition.

\section{REFERENCES}

[1] M. T. Restivo, J. C. Alves and A. Cardoso. “Experiment@Portugal”, International Journal of Engineering Pedagogy (iJEP), vol. 1(1), 2011, pp. 46-49.

[2] M. E. Auer, D. G. Zutin, C. Maier and N. Michael. "Lab2go - a Semantic Framework to Exchange and Publish Online Laboratories”, REV 2010, pp. 133-138, Stockholm, Sweden.

[3] José Couto Marques, Joana Quintela, Maria Teresa Restivo and Vasco Trigo, "The Use of Video Clips in Engineering Education", $15^{\text {th }}$ International Conference ICL, September 26-28, 2012.

\section{AUTHORS}

M. T. Restivo is with the UISPA, IDMEC-Pólo FEUP and with the Mechanical Department at the Faculdade de Engenharia, Universidade do Porto, Rua Dr. Roberto Frias, 4200-465 Porto, Portugal (e-mail: trestivo@fe.up.pt).

A. Cardoso is with the CISUC - Centre for Informatics and Systems of the University of Coimbra, Department of Informatics Engineering, University of Coimbra, Polo II, 3030-290 Coimbra, Portugal (e-mail: alberto@dei.uc.pt).

This work was partially supported by the Experiment@Portugal project, funded by the Calouste Gulbenkian Foundation. It is an extended and modified version of a paper presented at the International Conference on Remote Engineering \& Virtual Instrumentation (REV2012), held at University of Deusto, Bilbao, Spain, July 4-6, 2012. Received, 9 November 2012. Published as resubmitted by the authors 18 december 2012. 